Revista Brasileira de

Engenharia Agrícola e Ambiental

v.16, n.2, p.200-208, 2012

Campina Grande, PB, UAEA/UFCG - http://www.agriambi.com.br

agriambi Protocolo s4.11 - 07/04/2011 • Aprovado em 30/11/2011

\title{
Fertigação do algodoeiro utilizando efluente doméstico tratado ${ }^{1}$
}

\author{
O svaldo N. Sousa Neto ${ }^{2}$, Jerônimo Andrade Filho ${ }^{3}, \mathrm{Nildo}$ da S. Dias', \\ Jonatas R. L. Rebouças ${ }^{2}$, Francisco R. A. de Oliveira ${ }^{4}$ \& Adriana A. Diniz ${ }^{2}$
}

\section{RESU MO}

Conduziu-se um experimento no Campus da U niversidade Federal Rural do Semiárido em Mossoró, RN, com o objetivo de avaliar o comportamento do algodoeiro (Gossypium hirsutum L. raça latifolium $\mathrm{H}$ atch) cultivar $8 \mathrm{H}$, quanto ao aspecto crescimento, quando irrigado com efluentes domésticos tratados. 0 delineamento experimental adotado foi o de blocos casualizados com parcelas subdivididas e sendo testadas, nas parcelas, as diluições do efluente doméstico [25\% - $\mathrm{T}_{1}, 50 \%-\mathrm{T}_{2}, 75 \%-\mathrm{T}_{3}$ e $100 \%$ de água residuária- $\mathrm{T}_{4}$ e água de abastecimento + adubação mineral do solo $\left.-\mathrm{T}_{5}\right]$ em dois solos de texturas contrastantes (Latossolo Vermelho Amarelo - $\mathrm{S}_{1}$ e Cambissolo - $\mathrm{S}_{2}$ ). A irrigação com água residuária influenciou significativamente o crescimento das plantas de algodoeiro, em referência ao índice de velocidade de emergência, à percentagem de germinação à altura de plantas, ao diâmetro caulinar e número de folhas e à área foliar e massa seca de parte aérea, crescendo com o aumento da proporção de uso do efluente doméstico. Houve efeito positivo do acúmulo de nutrientes no solo aplicados via fertirrigação sobre as variáveis estudadas. A fertirrigação com efluente doméstico tratado pode substituir a adubação convencional do algodoeiro.

Palavras-chave: Gossypium hirsutum L., reúso, biometria

\section{Fertigation of cotton with treated domestic sewage}

\section{A B STRAC T}

An experiment was conducted at the U niversidade Federal Rural do Semi-arid in M ossoró, RN with the aim of evaluating the behavior of cotton (Gossypium hirsutum L. race latifolium $\mathrm{H}$ atch) $8 \mathrm{H}$ cultivar, in terms of grow th when irrigated with treated domestic sewage. The experimental design was in randomized blocks with split plots and in plots were tested dilutions of wastewater [25\%-T1, $50 \%-\mathrm{T} 2,75 \%-\mathrm{T} 3$ and $100 \%$ of wastewater - T4 and supply water with mineral fertilizer - T5] in tw o soils of contrasting textures. Irrigation with wastewater significantly influenced the growth of cotton plants, the rate of emergence, the germination percentage, plant height, stem diameter and leaf area, growing linearly until an optimal dose, as the proportion of use of domestic effluent. The positive effect of the accumulation of nutrient in soil applied by fertigation on the variables studied is also highlighted. The irrigation with treated wastewater can offset conventional fertilization of cotton.

Kew words: Gossypium hirsutum L., reuse, biometry

${ }^{1}$ Parte da Dissertação de M estrado do segundo autor. Trabalho apresentado durante a II Reunião Sulamericana para Manejo e Sustentabilidade da Irrigação em Regiões Áridas e Semiáridas, Cruz das Almas, BA - 03 a 07 de abril de 2011

2 Departamento de Ciências Ambientais e Tecnológica/UFERSA, C.P. 137, 59625-900, Mossoró, RN. E-mail: neto2006osvaldo@yahoo.com.br; nildo@ufersa.edu.br; rafaelufersa@hotmail.com, ronaldoindep@yahoo.com.br, adrisolos@bol.com.br

3 UNP, CEP 59625-900, Mossoró, RN. E-mail: jeronimoandrade@hotmail.com

${ }^{4}$ Departamento de Ciências do Solo/ Campus do Pici, Bloco 807, UFC, CEP 60455-760, Fortaleza, CE. E-mail: ronaldoindep@yahoo.com.br 


\section{INTRODUÇÃO}

A água potável, utilizada para sanar as necessidades básicas da população mundial, está cada vez mais escassa; necessitando de políticas de gerenciamento dos recursos hídricos, como forma de minimizar o impacto gerado pelas diversas atividades humanas.

Sob a ótica mundial é possível perceber que os recursos hídricos disponíveis não são mais suficientes para abastecer adequadamente a população. No Brasil, a escassez de água é bastante visível, sobretudo na região Nordeste na qual cerca de $58 \%$ do seu território, situado na região semiárida e caracterizada por apresentar curto período chuvoso, a temperatura é elevada e alta a taxa de evapotranspiração (Sousa et al., 2005).

Frente a este cenário, o reúso da água surge como alternativa viável na reversão desta situação de escassez. Diariamente grandes volumes de esgotos domésticos urbanos, sem qualquer tratamento ou controle, são lançados no ambiente, sobretudo em países subdesenvolvidos. Esta prática predatória é imensamente agressiva, causando incontáveis impactos negativos, sobremaneira ambientais e de saúde publica (Santos et al., 2006; Bezerra \& Fideles Filho, 2009).

Dessa forma, torna-se necessário a busca por alternativas racionais que viabilizem o uso de águas residuárias, tanto do ponto de vista ambiental como do ponto de vista econômico, sobretudo em regiões áridas e semiáridas cujos recursos hídricos são bastante escassos, a exemplo do Nordeste brasileiro. Neste sentido, uma alternativa racional de utilização das águas residuárias reside na prática da fertirrigação, notadamente de culturas cujo produto não se destina para fins comestíveis, como nos cultivos de oleaginosas para a produção de biodiesel, a exemplo do algodão (Alves et al., 2005; Bezerra et al., 2005; Figueiredo et al., 2005; Bezerra \& Fideles Filho, 2009) e do pinhão manso (Silva et al., 2011).

Segundo van Der Hoeck et al. (2002), a reutilização da água se apresenta vantajosa quando, com isto, é possível preservar os recursos hídricos disponíveis; contribuir para o aporte e a reciclagem de nutrientes, o que possibilita a diminuição da utilização de fertilizantes químicos e, finalmente, viabilizar a preservação ambiental. Silva et al. (2005) completam que o uso de esgoto tratado para as atividades agrícolas é proporcionar economia de fertilizante e de água de boa qualidade podendo, ainda, ser uma alternativa para convivência com sua escassez.

Apesar dos vários benefícios evidenciados, a utilização de esgotos domésticos tratados na agricultura requer práticas tecnicamente adequadas de tratamento e de disposição no ambiente, pois as águas residuárias, além de apresentarem consideráveis concentrações de íons dissolvidos como o sódio, o boro e cloretos, contêm grande variedade de organismos patogênicos como bactérias, vírus, protozoários e helmintos. Tais características se têm constituído como cenário dificultador na utilização de esgotos domésticos tratados na agricultura (Sousa et al., 2003).

Neste sentido, foi desenvolvido este ensaio experimental, com o objetivo de analisar o efeito da fertirrigação com esgoto doméstico sobre aspectos de crescimento do algodão herbáceo
(Gossypium hirsutum L. raça latifolium Hatch, cv.8H), tendo em vista sua importância e aplicabilidade como cultura de interesse econômico e como via de subsistência na agricultura familiar do Nordeste do Brasil.

\section{MATERIAL E MÉTODOS}

O experimento foi conduzido no período de novembro de 2009 a março de 2010, na área experimental do Departamento de Ciências Ambientais e Tecnológicas da Universidade Federal Rural do Semiárido (UFERSA), em Mossoró, RN (5 $11^{\prime}$ de latitude Sul e $37^{\circ} 20^{\prime}$ de longitude Oeste de Greenwich e com altitude de $18 \mathrm{~m}$ ). O clima local é do tipo BSwh' com base na classificação de Köppen e a média anual de precipitação é da ordem de $678 \mathrm{~mm}$. As médias anuais de temperatura, insolação e umidade relativa são $27,4{ }^{\circ} \mathrm{C} ; 2360$ horas anuais e $68,9 \%$, respectivamente (Carmo Filho \& Oliveira, 1995).

O esgoto urbano, proveniente da lagoa de estabilização da Estação de Tratamento de Esgotos Domésticos das Cajazeiras em Mossoró, RN, pertencente à CAERN (Companhia de Água e Esgoto do Rio Grande do Norte), localizada na comunidade Passagem de Pedras, foi transportado semanalmente da lagoa de estabilização até o local do experimento em reservatório de $1000 \mathrm{~L}$, sendo este o volume suficiente para a preparação da água de irrigação a ser usada durante uma semana. A água potável era proveniente do sistema de abastecimento público do campus da UFERSA. Os resultados das análises físico-químicas e microbiológicas do esgoto doméstico secundário utilizado nos ensaios experimentais estão disponíveis na Tabela 1.

O ciclo de cultivo teve duração de 115 dias após o plantio (DAP), em que foram realizadas avaliações com o algodão comparando-se o efeito da fertirrigação com diferentes diluições de água residuária com água potável do sistema de abastecimento público da UFERSA, com adubação mineral (testemunha) e dois tipos de solos.

O delineamento experimental adotado foi o de blocos casualizados com parcelas subdivididas, sendo que em nível de parcelas foram testadas as diluições do efluente doméstico em água de abastecimento a $25 \%-\mathrm{T}_{1}, 50 \%-\mathrm{T}_{2}, 75 \%-\mathrm{T}_{3} \mathrm{e}$ $100 \%$ de água residuária $-\mathrm{T}_{4} \mathrm{e}$, como testemunha, água de abastecimento + adubação mineral no solo - $\mathrm{T}_{5}$. As subparcelas se constituíram de dois solos de textura contrastante (Latossolo Vermelho Amarelo - $\mathrm{S}_{1}$ e Cambissolo - $\mathrm{S}_{2}$ ). Os tratamentos foram dispostos em 20 parcelas experimentais com $1 \mathrm{~m}^{2}(0,50 \times 2,00$ $\mathrm{m})$, em que cada parcela foi subdividida em duas subparcelas (solos), totalizando 40 unidades experimentais, sendo 5 diluições, dois tipos de solo e 4 repetições.

Inicialmente, cada subparcela era composta de duas fileiras de plantas, com oito plantas por metro linear, espaçadas $0,15 \mathrm{~m}$ entre fileiras e $1 \mathrm{~m}$ entre subparcelas. Em cada subparcela foram consideradas úteis apenas quatro plantas centrais. Os tratamentos foram isolados entre si utilizando-se divisões subterrâneas de $0,50 \mathrm{~m}$ de profundidade, constituídas de filme de polietileno a fim de evitar prováveis contaminações entre os tratamentos. 
Tabela 1. Características físico-químicas e microbiológicas do efluente de esgoto tratado utilizado na irrigação do al godoeiro

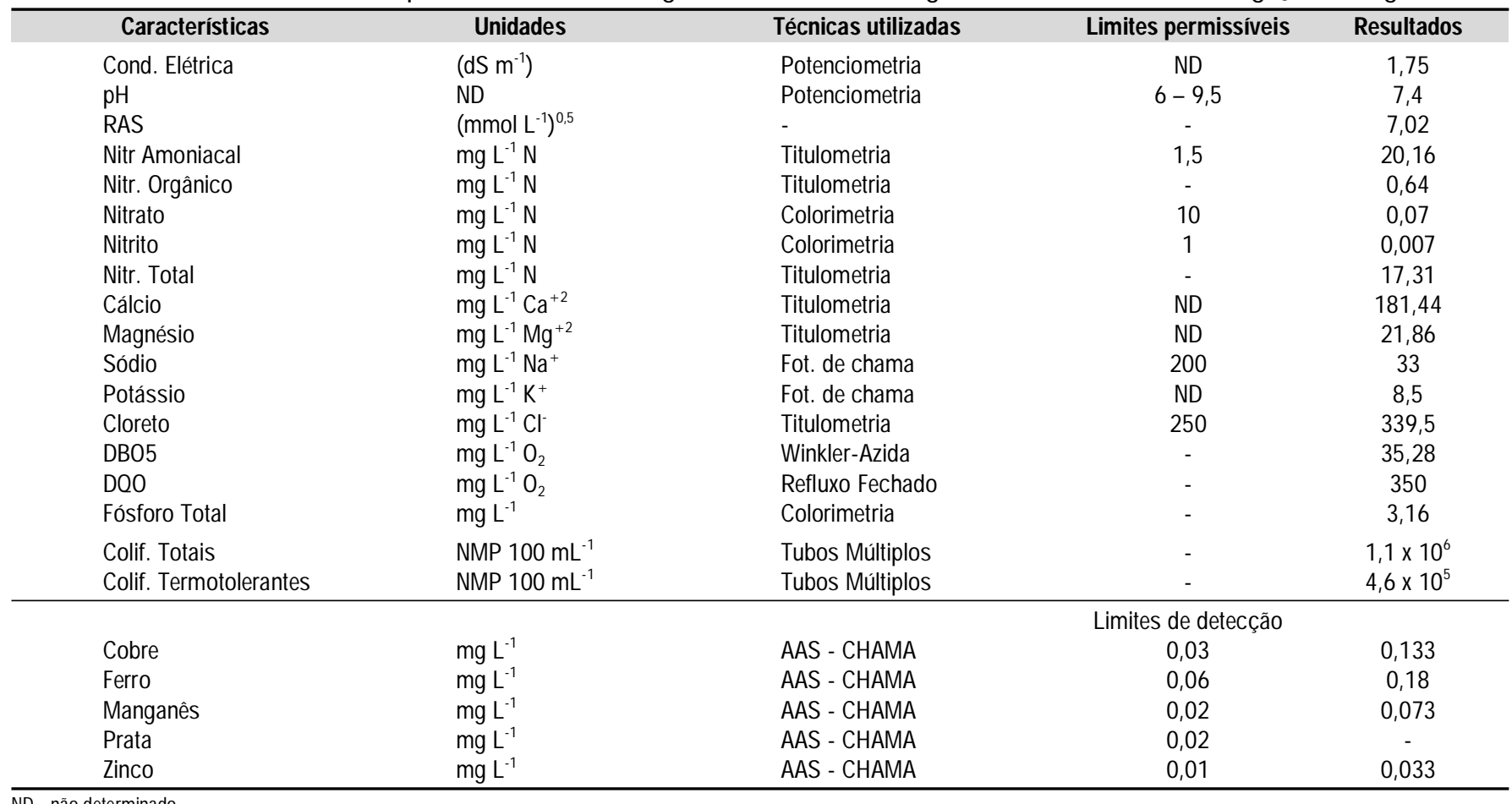

ND - não determinado

As parcelas experimentais foram divididas utilizando-se alvenaria de tijolo e em seguida preenchidas com $315 \mathrm{~kg}$ do solo $S_{1}$ e $288 \mathrm{~kg}$ de solo $\mathrm{S}_{2}$. Os solos para a condução do experimento foram extraídos da camada de 0 a $20 \mathrm{~cm}$ do perfil, em áreas de solo virgem. $\mathrm{O}$ solo arenoso foi coletado em área de mata, na Fazenda experimental da UFERSA "Rafael Fernandes", distante $21 \mathrm{~km}$ de Mossoró. O solo argiloso foi extraído em área de solo virgem, pertencente à Empresa WG Fruticultura, localizada na zona rural do município de Baraúna, RN, distante cerca de $30 \mathrm{~km}$ da sede do município de Mossoró, RN. Os materiais coletados foram postos para secar, mas não foi realizada alteração alguma na estrutura do solo buscandose simular, com maior proximidade, as condições de campo.

Subamostras foram retiradas de cada material de solo, visando à caracterização física e química, de conformidade com metodologia recomendada pela EMBRAPA (1997) (Tabela 2).

Quarenta e oito sementes foram semeadas por subparcela, duas linhas de vinte e quatro, implantadas de forma equidistante com profundidade variando entre 2,5 a $3,0 \mathrm{~cm}$, visando avaliar a influência dos tratamentos na germinação da cultura. Antes da semeadura as parcelas foram irrigadas até a capacidade de campo determinada pela capacidade de retenção de água de cada solo.

Foi necessária a realização da calagem do solo arenoso nas parcelas que receberam adubação química $\left(\mathrm{T}_{5}\right)$, visando à elevação da sua saturação por bases para $70 \%$, para o que se utilizou uma dosagem calculada de $1,67 \mathrm{t} \mathrm{ha}^{-1}$ de calcário dolomítico que, além de elevar a saturação por bases, fornece uma quantidade considerada de magnésio.

Para incorporação do calcário elevou-se a umidade do solo até a capacidade de campo, procedendo com a incorporação nas parcelas. Procurou-se realizar uma mistura homogênea do calcário ao solo, haja vista estar disponível um período de 15 dias para a reação.

Após a realização da calagem do solo se determinaram a necessidade de adubação de fundação e a cobertura para o tratamento utilizando-se apenas água de abastecimento para irrigação, segundo a recomendação da EMBRAPA (2006), para o cultivo do algodoeiro herbáceo cultivado no cerrado. De acordo com os teores nos solos e uma produtividade esperada de $5 \mathrm{t} \mathrm{ha}^{-1}$, utilizaram-se doses de adubação $\mathrm{Ne} \mathrm{P}$ em fundação iguais a $25 \mathrm{~kg} \mathrm{ha}^{-1}, 90 \mathrm{~kg} \mathrm{ha}^{-1} \mathrm{em}$ particular o K, cuja aplicação,

Tabela 2. Caracterização física e química dos solos utilizados

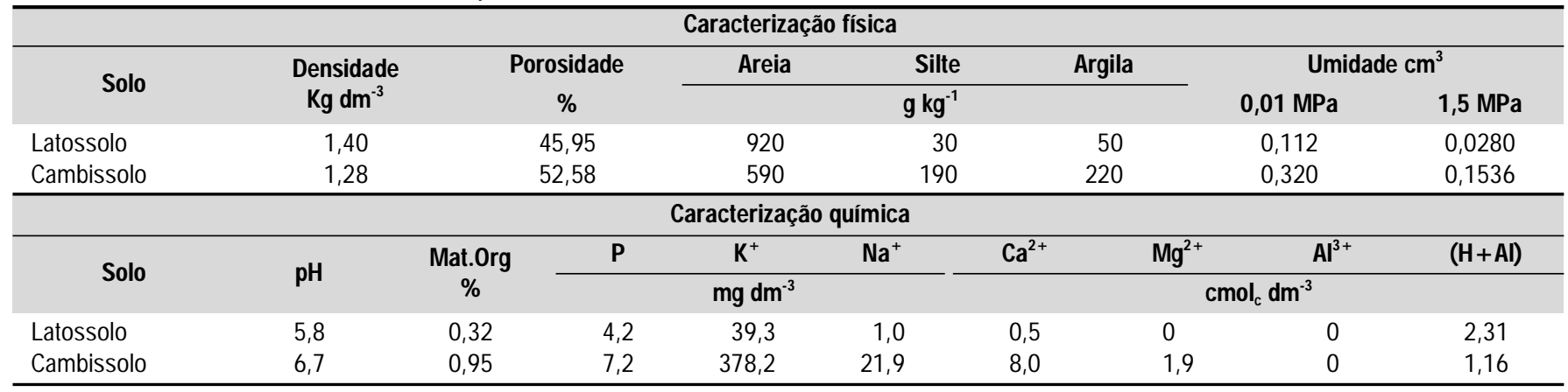


foi de $30 \mathrm{~kg} \mathrm{ha}^{-1}$, somente para o solo arenoso. Além disto, foram recomendados $40 \mathrm{~kg} \mathrm{ha}^{-1}$ de enxofre, via sulfato de magnésio para os dois solos, visto que o algodoeiro é bastante exigente quanto a este elemento.

Em adubação de cobertura foram aplicados $125 \mathrm{~kg} \mathrm{ha}^{-1}$ de nitrogênio para os dois solos e, no caso do potássio, 140 $\mathrm{kg} \mathrm{ha}^{-1}$ para o solo arenoso. A aplicação de cobertura foi parcelada em duas etapas, a primeira 25 dias após a emergência, quando então se aplicaram: metade do nitrogênio e $40 \%$ do potássio recomendados; já na segunda etapa do parcelamento foram aplicados o restante do nitrogênio e o potássio, no início do florescimento, ou seja, aos 50 dias após o plantio, enquanto os outros tratamentos receberam esses elementos na fertirrigação com água residuária, até os 100 DAP.

O calcário foi incorporado manualmente a uma camada de 20-30 cm de profundidade, enquanto para adubação de fundação os nutrientes foram aplicados em sulcos com aproximadamente $10 \mathrm{~cm}$ de profundidade; enfim, a adubação de cobertura foi realizada mediante fertirrigação.

Adotou-se o sistema de irrigação localizada utilizando-se emissores tipo microtubos de 1,5 mm de diâmetro interno, visando evitar entupimento pelas partículas em suspensão presentes no efluente. $\mathrm{O}$ fornecimento de água foi realizado através de reservatórios individuais, com capacidade de $310 \mathrm{~L}$ cada um, suspensos sobre uma estrutura construída com tijolos e madeira, de forma a se obter uma coluna de água de 1,2 m; Os reservatórios eram preenchidos semanalmente, com os volumes correspondentes a cada tratamento.

O sistema de distribuição de água se compunha de cinco linhas laterais com diâmetro de $14 \mathrm{~mm}$, uma para cada tratamento, individualmente, ao longo de cada bloco e de acordo com a aleatorização das parcelas. Foram instalados oito microtubos nas linhas laterais de cada parcela, espaçados $0,25 \mathrm{~m}$, sendo tal espaçamento necessário para o encontro entre os bulbos, visando formar uma única área molhada dentro da parcela. Além disso, utilizaram-se microtubos de 2,00 $\mathrm{m}$ de comprimento para cada emissor, comprimento este predefinido em testes, de forma que se obteve uma vazão média de $3,3 \mathrm{~L} \mathrm{~h}^{-1}$. O índice de velocidade de emergência foi determinado mediante a contagem diária do número de plântulas e a percentagem de germinação com a estabilização da emergência aos 5 dias; obteve-se a altura das plantas medindo-se do colo da planta até o ápice (meristema apical) e, quanto ao diâmetro do caule, as medições foram realizadas a um centímetro em relação à superfície do solo.

A área foliar foi medida aos 15, 30 e 50 dias após o plantio, realizada pelo desbaste das plantas em excesso e determinada através de um integrador de área, marca LI-COR, modelo LI3100. O acúmulo de fitomassa foi medido no mesmo momento da área foliar, tendo-se coletado a parte aérea (caule e folha) de quatro plantas de cada subparcela, as quais foram postas para secagem em estufa de circulação forçada de ar, na temperatura de $60{ }^{\circ} \mathrm{C}$ até atingir peso constante, sendo o material pesado em balança de precisão de $0,01 \mathrm{~g}$, obtendo a fitomassa seca da parte aérea.

As médias dos resultados foram comparadas pelo teste de F $(5 \%)$ e submetidas a análise de regressão com auxilio do programa SISVAR.

\section{RESULTADOS E DISCUSSÃO}

Na Tabela 3 tem-se os resultados da análise de variância referentes à percentagem de emergência $(\mathrm{PG})$ e ao índice de velocidade de emergência (IVE) do algodoeiro. Observa-se que houve efeito significativo $(p \geq 0,05)$ das proporções de água residuária sobre a percentagem de germinação e índice de velocidade de emergência. Para o tipo de solo verificou-se efeito significativo ( $\mathrm{p} \geq 0,01)$ para PG e IVE e não houve efeito da interação fontes de nutrientes $\mathrm{x}$ tipo de solo.

Tabela 3. Resumo da análise de variância, médias para percentagem de germinação (PG) e indice de velovidade de emergencia (IVE) de plântulas de algodoeiro submetidas a percentagens crescentes de uso de água residuária e adubação química, em dois solos

\begin{tabular}{|c|c|c|c|}
\hline \multirow{2}{*}{ FV } & \multirow{2}{*}{ GL } & \multicolumn{2}{|c|}{ Estatística F } \\
\hline & & PG & IVE \\
\hline $\begin{array}{l}\text { Fonte de Nutrientes (FN) } \\
\text { Propor. AR. } \\
\text { E. Linear } \\
\text { E. Quadrático }\end{array}$ & $\begin{array}{l}4 \\
3 \\
1 \\
1\end{array}$ & $\begin{array}{l}2,95^{\mathrm{NS}} \\
3,74^{*} \\
9,42^{*} \\
0,96^{\mathrm{NS}}\end{array}$ & $\begin{array}{l}2,74^{\mathrm{NS}} \\
2,89^{\mathrm{NS}} \\
2,54^{\mathrm{NS}} \\
6,08^{*}\end{array}$ \\
\hline $\begin{array}{l}\text { Erro } 1 \\
\text { Solo (S) } \\
\text { FN X S } \\
\text { Erro } 2\end{array}$ & $\begin{array}{r}12 \\
1 \\
4 \\
15\end{array}$ & $\begin{array}{c}27,81^{* *} \\
2,49^{\text {NS }}\end{array}$ & $\begin{array}{c}48,34^{* *} \\
1,27^{\mathrm{NS}}\end{array}$ \\
\hline $\begin{array}{l}\text { C.V. (a) } \\
\text { C.V.(b) }\end{array}$ & & $\begin{array}{l}8,04 \\
5,98 \\
\end{array}$ & $\begin{array}{l}12,18 \\
10,18 \\
\end{array}$ \\
\hline \multirow{2}{*}{\multicolumn{2}{|c|}{ Fonte de nutrientes }} & \multicolumn{2}{|c|}{ Médias } \\
\hline & & $(\%)$ & (plântulas dia-1) \\
\hline $\begin{array}{l}\mathrm{T}_{1}(25 \% \text { res }) \\
\mathrm{T}_{2}(50 \% \text { res }) \\
\mathrm{T}_{3}(75 \% \text { res }) \\
\mathrm{T}_{4}(100 \% \text { res }) \\
\mathrm{T}_{5} \text { (Ad. Mineral) }\end{array}$ & & $\begin{array}{l}83,33 \\
87,24 \\
93,75 \\
92,71 \\
91,93\end{array}$ & $\begin{array}{l}28,42 \\
32,75 \\
34,18 \\
31,38 \\
33,56 \\
\end{array}$ \\
\hline \multicolumn{4}{|l|}{ Solo } \\
\hline $\begin{array}{l}\text { Latossolo }\left(\mathrm{S}_{1}\right) \\
\text { Cambissolo }\left(\mathrm{S}_{2}\right)\end{array}$ & & $\begin{array}{l}85,31 b \\
94,27 a\end{array}$ & $\begin{array}{l}28,40 \mathrm{~b} \\
35,71 \mathrm{a}\end{array}$ \\
\hline
\end{tabular}

A percentagem de germinação (PG) apresentou comportamento linear, ou seja, cresceu em função do aumento da concentração de água residuária, atingindo o valor máximo de PG $(94,45 \%)$ com $100 \%$ de água residuária (Figura 1A). É provável que esse efeito positivo no crescimento tenha ocorrido em função do caráter fertilizante que os efluentes domésticos possuem (Bezerra \& Fideles Filho, 2009).

$O$ índice de velocidade de emergência (IVE) foi influenciado pela proporção de água residuária tratada, observando-se que a resposta do algodão pode ser estimada por equação quadrática, apresentando coeficiente de determinação satisfatótio $\left(\mathrm{R}^{2}>0,90\right)$. Desta forma, o máximo IVE foi encontrado na proporção de água residuária, de 68,57\% (33,83 plântula dia $^{-1}$ ) sendo que existe, a partir desta proporção, tendência de redução no número de plântulas dia-1 (Figura 1B).

Verifica-se, pela análise multivariada, que a interação dias $\mathrm{x}$ tratamento exerceu efeitos significativos sobre a altura de plantas e o diâmetro do caule, a nível de $1 \%$ de significância para o Latossolo (Tabela 4); já o número de folhas não foi influenciado pela interação e as variáveis altura de planta, 


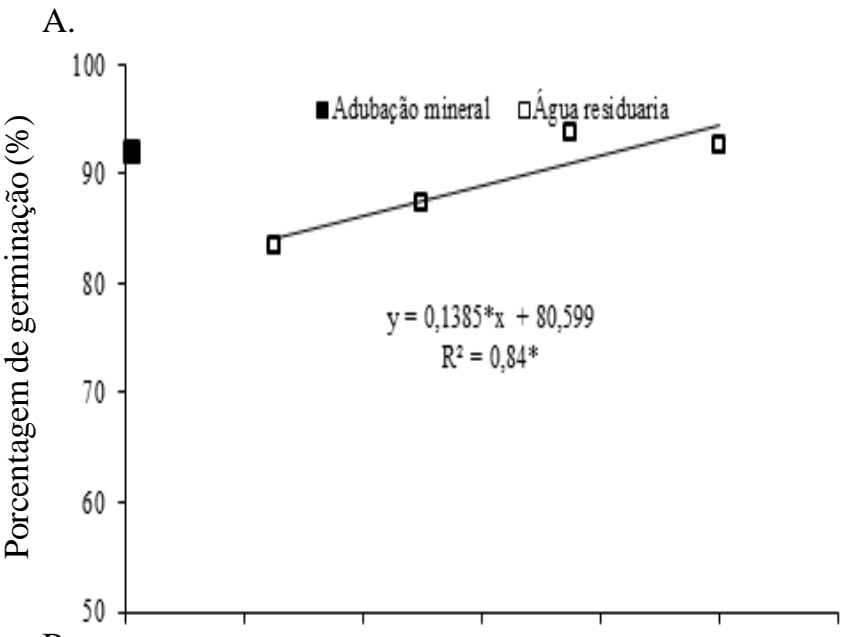

B.

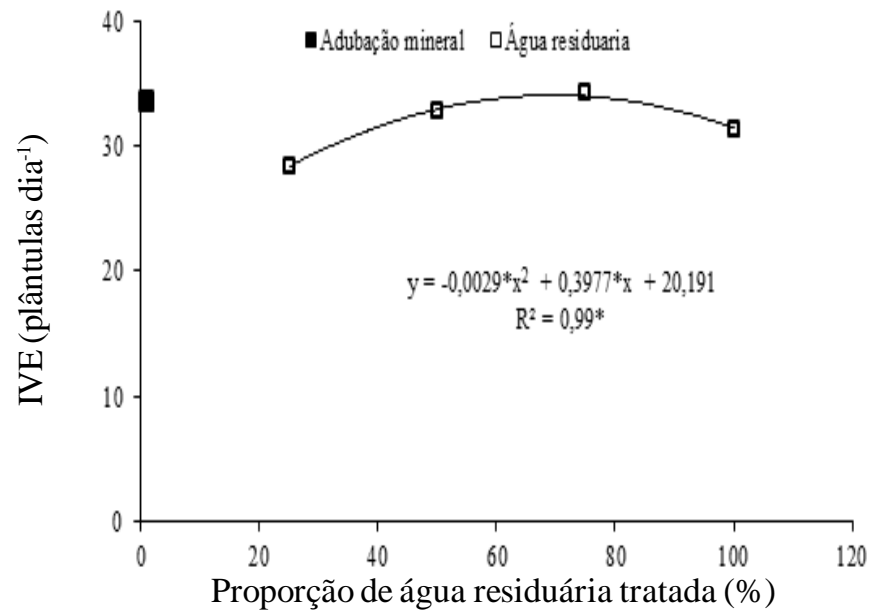

Figura 1. Percentagem de germinação $(A)$ e índice de velocidade de emergência - IVE (B), em função do aumento percentual das diluições do efluente doméstico em água de abastecimento

diâmetro do caule e número de folhas, responderam significativamente aos efeitos da fonte de variação proporção de água residuária para os solos Latossolo e Cambissolo.

Na avaliação da variável altura de planta no Latossolo (Figura 2A) e Cambissolo (Figura2B), verifica-se incremento dessa variável sempre que foi aumentado o percentual de uso de água residuária na fertirrigação do algodoeiro cultivado no solo Latossolo. Observou-se ainda que, a partir dos 50 dias após o plantio, as plantas que receberam apenas água residuária na fertirrigação (100\%) apresentaram maior altura de plantas (Figura 2A), em relação aos demais tratamentos, com os valores sendo elevados de $50,48 \mathrm{~cm}$ aos 50 dias para até $74,44 \mathrm{~cm}$ aos 115 dias após o plantio, até então, referido comportamento comportamento muito semelhante ao anterior, com os valores crescendo com o aumento dos dias após a emergência, com
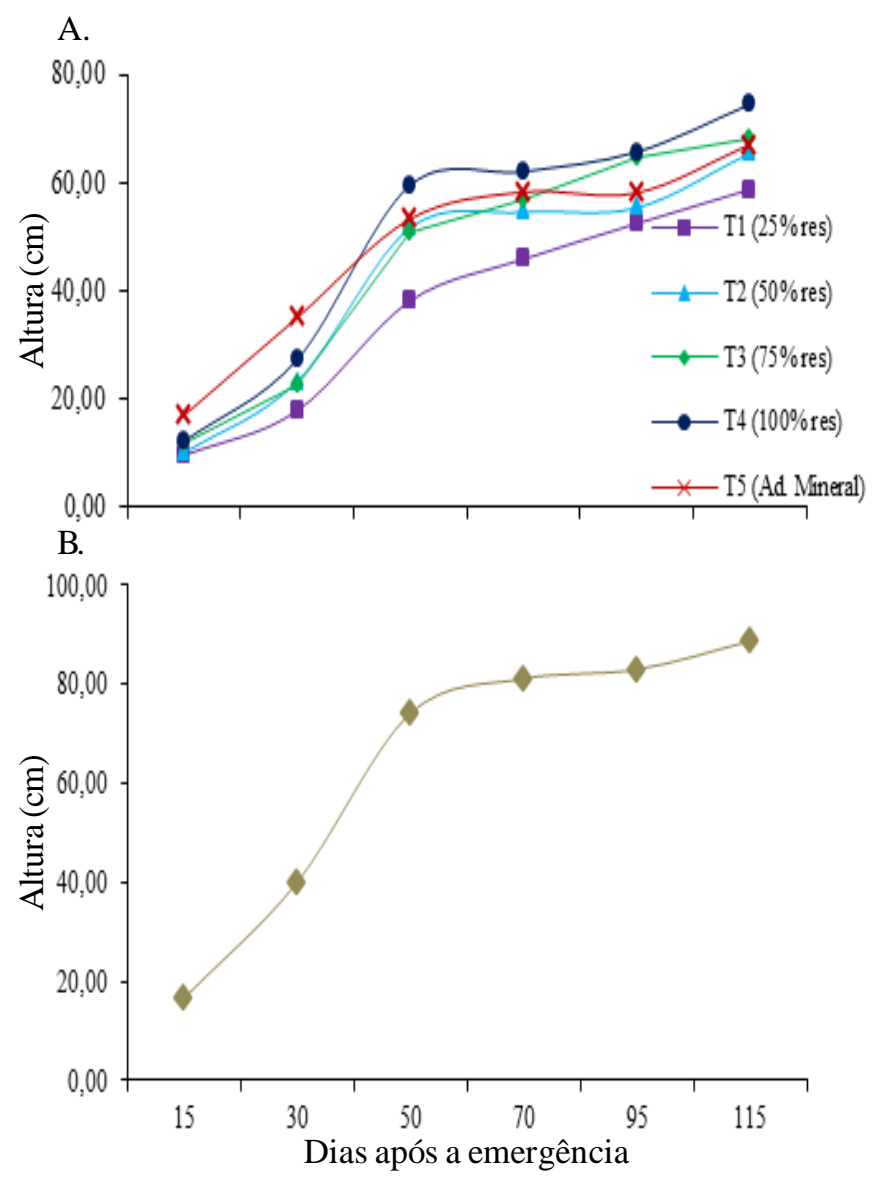

Figura 2. Altura de planta de algodoeiro para as percentagem de uso de agua residuária tratada e adubação mineral no Latossolo (A) e Cambissolo (B), em função dos dias após a emergência

havia sido constatado nos tratamentos que receberam apenas adubação convencional.

Para Bezerra \& Fideles Filho (2009) esta superioridade nos tratamentos água residuária ocorre, possivelmente, em razão das águas residuárias provenientes de esgotos urbanos pretratados exercerem efeito fertilizantes sobre a cultura do algodão, conforme os autores evidenciaram na evolução temporal da fitomassa e da área foliar tornando-se, a partir daí, uma alternativa relevante na adoção da prática de fertirrigação, principalmente de culturas cujos produtos não se destinam ao consumo humano.

Constata-se, na Figura 2B, a média de altura de plantas para todos os tratamentos aplicados no Cambissolo e o

Tabela 4. Resumo da análise multivariada (Estatística de W ilk's Lambda) das características de crescimento do algodão ' $\mathrm{CV} 8 \mathrm{H}$ ' durante o ciclo da cultura, em função da aplicação de água residuária

\begin{tabular}{|c|c|c|c|c|c|c|}
\hline \multirow{3}{*}{ Fonte de variação } & \multicolumn{6}{|c|}{ Variáveis } \\
\hline & \multicolumn{2}{|c|}{ Altura de plantas $(\mathrm{cm})$} & \multicolumn{2}{|c|}{ Diâmetro do caule $(\mathrm{cm})$} & \multicolumn{2}{|c|}{ Número de folhas } \\
\hline & Latossolo & Cambissolo & Latossolo & Cambissolo & Latossolo & Cambissolo \\
\hline Trat. (Perfis coincidentes) & $3,61 *$ & $2,69^{\mathrm{NS}}$ & $13,93 * *$ & 3,09 NS & $2,38^{\mathrm{NS}}$ & $1,88^{\mathrm{NS}}$ \\
\hline Dias (Perfis horizontais) ${ }^{1 /}$ & $208,35^{* *}$ & $391,12 * *$ & $562,91 * *$ & $577,43 * *$ & $336,05 * *$ & $862,38 * *$ \\
\hline Dias * Trat (Perfis paralelos) $)^{21}$ & $0,0019 * *$ & 1,72 Ns & $3,18 * *$ & $1,86^{\text {NS }}$ & 1,72 NS & $0,77^{\text {NS }}$ \\
\hline
\end{tabular}


valores de altura variando de 16,64 a $88,71 \mathrm{~cm}$. O maior incremento de altura se manteve entre os 30 e 50 dias após a emergência, que possuem valores médios de 40,08 e 70,16 cm por planta, respectivamente, mas Siqueira et al. (2005) obtiveram comportamento semelhante, ao avaliarem o crescimento em altura, do algodoeiro colorido sob diferentes níveis de salinidade da água de irrigação, em função dos dias após a emergência.

Na Figura $3 \mathrm{~A}$ o uso de $100 \%$ de efluente aplicado via fertirrigação resultou em plantas com maiores ganhos em diâmetro caulinar, a partir dos 30 dias, permanecendo nesta condição até o final das leituras, com altura máxima obtida aos 70 dias após a emergência, com $9,92 \mathrm{~cm}$ por planta ${ }^{-1}$. No solo Cambissolo não houve diferenças entre os tratamentos aplicados (Figura 3B), sendo utilizado um perfil médio para representar os tratamentos. O diâmetro caulinar cresceu com o aumento dos dias, com valores partindo de 3,07 $\mathrm{mm}$ aos 15 dias para 12,02 mm aos 70 dias após a emergência cujos resultados corroboram com os obtidos por Siqueira et al. (2005) ao verificarem a mesma tendência de comportamento para o diâmetro do caule do algodoeiro (linhagem CNPA 2002/26 Cluster Marrom Escuro) quando fertirrigado com água de duas composições combinadas com seis níveis de salinidade da água de irrigação, e por Rodrigues et al. (2009), ao avaliarem o

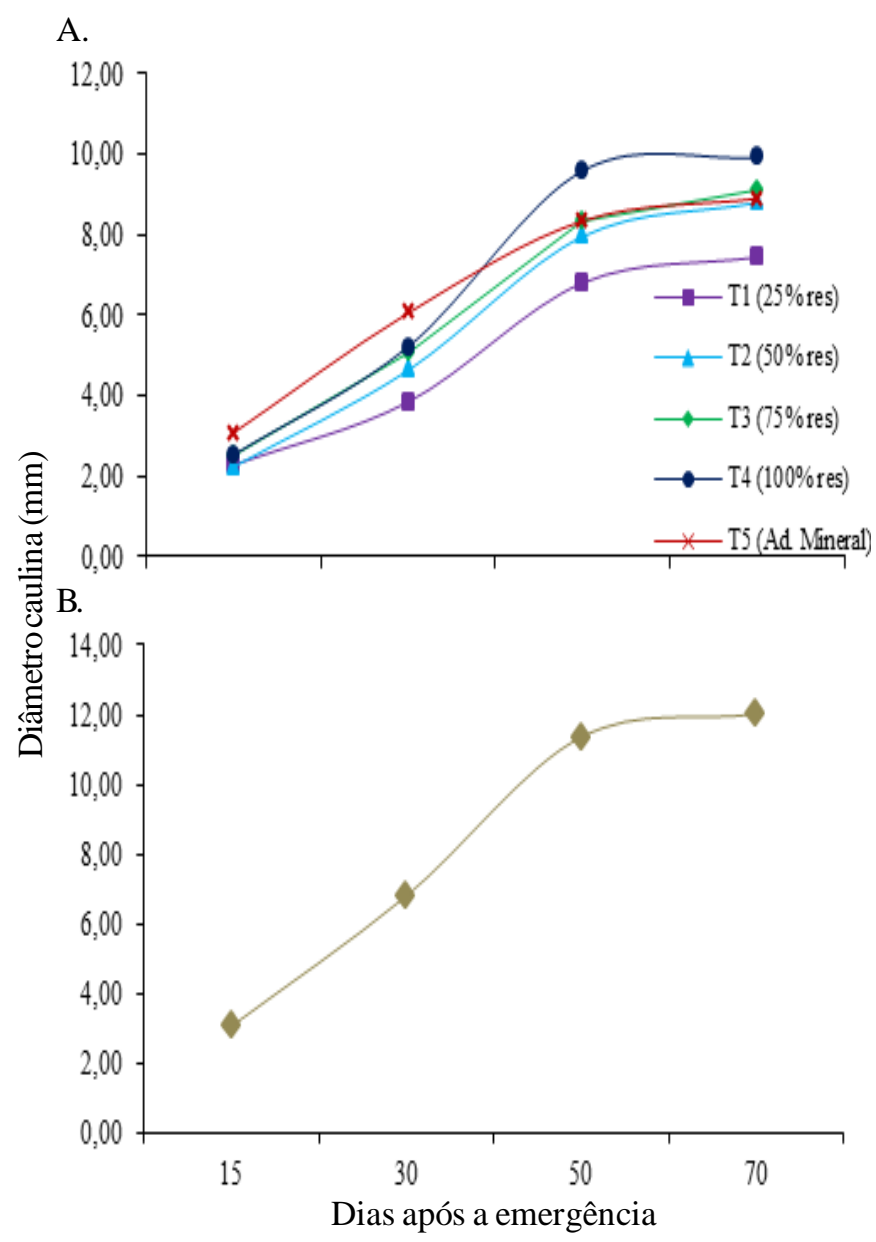

Figura 3. Diametro caulinar do algodoeiro para as percentagem de uso de água residuaria tratada e adubação mineral no Latossolo (A) e Cambissolo (B), em função dos dias após a emergência crescimento e produção de bagas da mamoneira irrigada com água residuária doméstica e verificando que o crescimento da mamoneira é favorecido pela irrigação com a água residuária de origem doméstica.

O número de folhas (Figura 4) cresceu com o aumento dos dias após a emergência para os solos Cambissolo e Latossolo, situando-se a maior média para o Cambissolo em relação ao Latossolo em todas as épocas de estudo, durante o ciclo cultural; no Cambissolo os valores foram elevados de 2,49 para 28,09 folhas planta ${ }^{-1}$ no intervalo compreendido dos 15 aos 95 dias após a emergência enquanto no Latossolo os valores aumentaram até os 50 dias após a emergência, com aumento de 2,10 para 16,96 folhasplanta ${ }^{-1 ;}$ a partir daí houve uma estabilização por alguns dias e depois redução no número de folhas, o que é absolutamente normal devido à abscisão foliar uma vez que, uma vez que se inicia a senescência da cultura. Este comportamento também foi verificado por Siqueira et al. (2005) na cultura do algodoeiro, e por Alves et al. (2009a) ao constatarem que a utilização de água residuária tratada em irrigação promoveu adequado crescimento e desen volvimento adequado, do algodoeiro de fibras marrons.

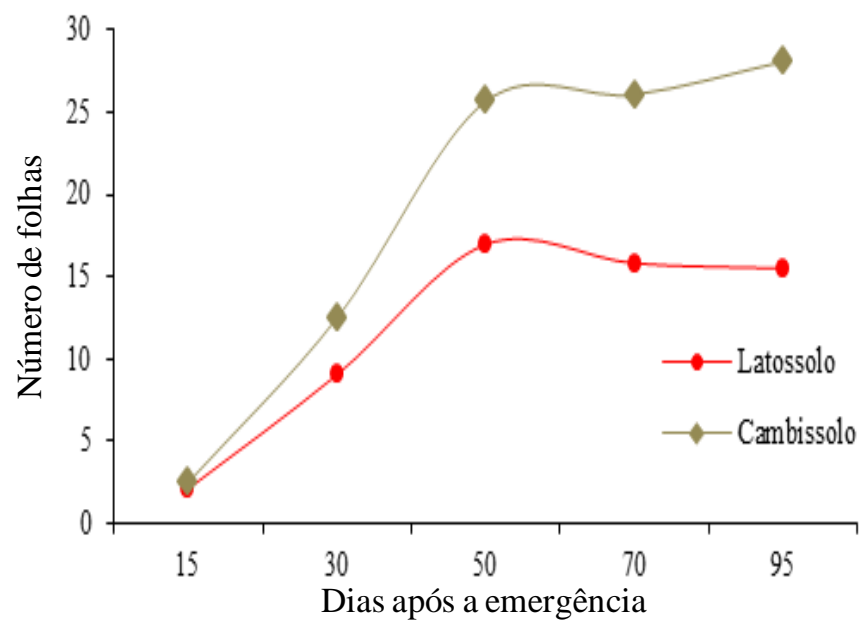

Figura 4. Número de folhas do algodoeiro para os solos Cambissolo e Latossolo em função dos dias após a emergência

Apenas aos 15 dias após o plantio a AF e a MSPA do algodoeiro foram influenciadas significativamente pela interação fonte de nutrientes x solos. Com relação ao efeito isolado dos solos para a variável AF e MSPA, verifica-se que houve efeito significativo a $1 \%$ de probabilidade em todas as épocas analisadas. Observandose as médias para os solos é possível constatar que o Cambissolo apresentou melhor desempenho quando comparado com o Latossolo em relação à AF e MSPA (Tabela 5).

Aos 15 DAP a resposta da matéria seca da parte aérea (MSPA) não se ajustou a nenhum modelo linear ou quadrático; contudo, na Figura 5A estão dispostas as médias referentes ao comportamento da MSPA em função das proporções de água residuária para os solos analisados; aos $30 \mathrm{DAP}$, quando irrigado com esgoto tratado, a resposta foi linear, apresentando valor máximo para a matéria seca de 3,46 g com $100 \%$ de água residuária (Figura 5B); já aos 50 DAP, a matéria seca global da parte aérea, quando irrigada com água residuária, apresentou 
Tabela 5. Resumo da análise de variância e médias para as variáveis área foliar e matéria seca da parte aérea aos 15, 30 e 50 dias após o plantio, submetidas a percentagens crescentes de uso de água residuária e adubação química em dois solos distintos

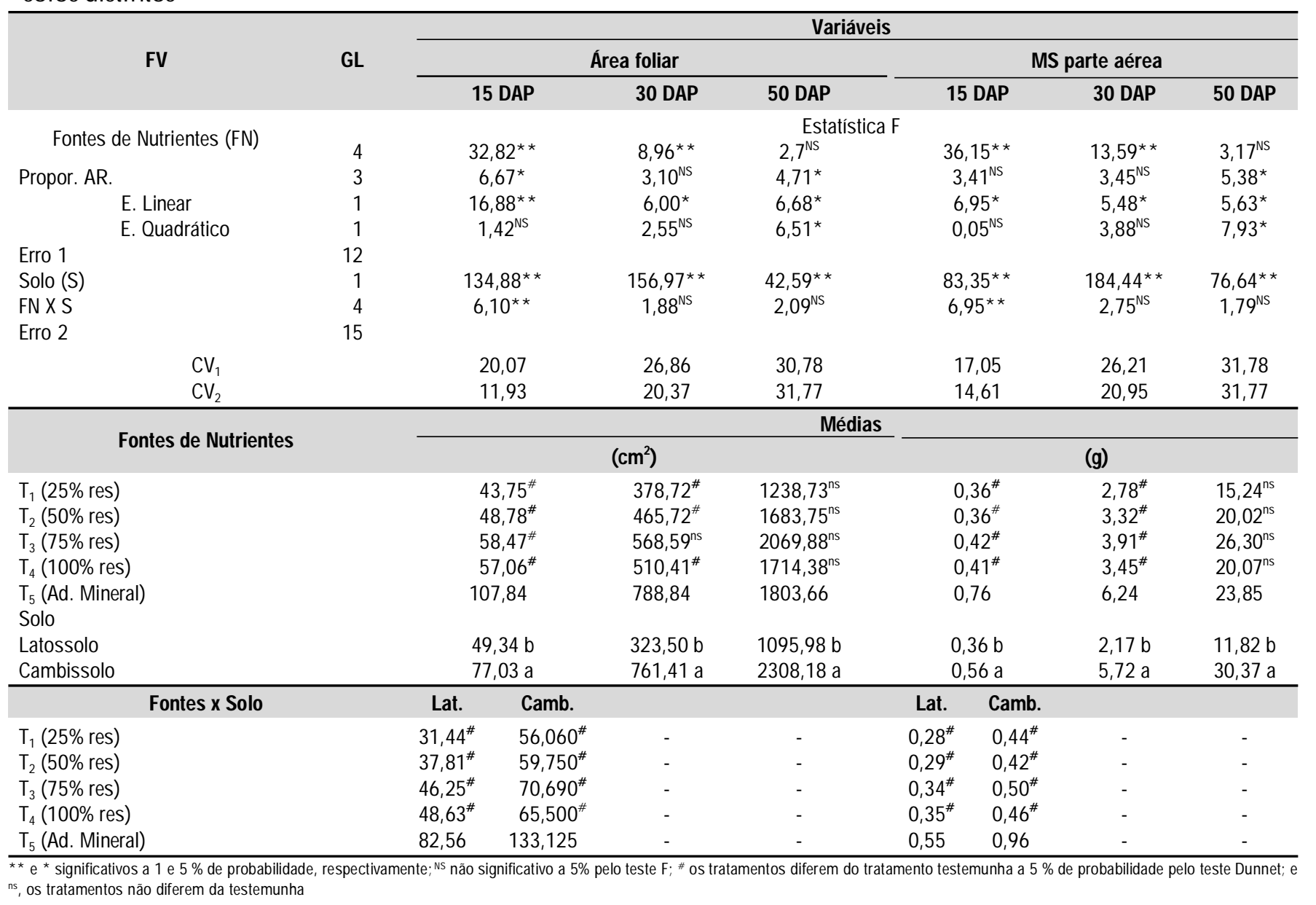

resposta quadrática $\left(\mathrm{R}^{2}>0,84\right)$, com um valor máximo de 24,27 g e aplicação de 72,01\% de água residuária (Figura 5C).

Os resultados da análise de variância para área foliar e matéria seca da parte aérea demonstraram não apenas que houve efeito significativo das fontes de nutrientes (proporções de água residuária e adubação mineral), a $1 \%$ de probabilidade, aos 15 , 30 e 50 DA, mas também interação significativa $(\mathrm{p}<0,01)$ entre a proporção de água residuária tratada e os dois tipos de solo, aos 15 DAP; por outro lado, a área foliar aumentou linearmente $(\mathrm{p}<0,05)$ com o aumento da proporção de uso da água residuária aos 15 e 30 DAP (Figura 6A e 6B); aos 50 DAP a área foliar se ajustou significativamente $(\mathrm{p}<0,05)$ ao modelo polinomial quadrático, em função do aumento das proporções de uso da água residuária, destacando-se ainda que o ponto de máximo da curva de ajuste apresentou valor superior ao expresso pelo tratamento testemunha (adubação mineral + água de abastecimento) para a área foliar (Figura 5C).

Com base no exposto, pode-se destacar o efeito acumulativo dos nutrientes aplicados via fertirrigação em função da percentagem de uso e do tempo de aplicação, vindo a compensar a baixa fertilidade inicial do solo e comprovar que as águas residuárias possuem efeito fertilizante. Comportamento semelhante a esses foram obtidos por Ferreira et al. (2005) que constataram diferenças apreciáveis entre a área foliar do algodoeiro irrigado com águas residuárias e irrigado com água de abastecimento e, por Fideles Filho et al. (2005), ao verificarem que o algodoeiro irrigado com esgotos decantados apresentou incremento na área foliar quase três vezes superior aos resultados apresentados pela mesma cultura submetida à mesma lâmina $\mathrm{e}$ ao mesmo turno de rega com águas de poço.

Bezerra \& Fideles Filho (2009) concluíram, ao estudar o crescimento da cultura do algodoeiro herbáceo (Gossipyum hirsutum) cultivar CNPA 8MH, irrigado com águas residuárias, que as águas residuárias provenientes de esgotos urbanos pretratados têm efeito fertilizantes sobre a cultura do algodão, conforme evidenciaram através da fitomassa e da área foliar tornando-se, desta forma, uma alternativa relevante na adoção da prática de fertirrigação. Alves et al. (2009b) verificaram, avaliando o efeito de lâminas de água residuária $(367,505,643$ e $781 \mathrm{~mm}$ ) na ausência e presença de nitrogênio e fósforo, nas doses de 90 e $60 \mathrm{~kg} \mathrm{ha}^{-1}$ de N e P, respectivamente, sobre a área foliar da planta do algodão de fibra marrom, que a área foliar das plantas irrigadas com água residuária foi maior que as irrigadas com água de abastecimento.

Por outro lado, Ferreira et al. (2003) concluíram, analisando parâmetros de crescimento do algodoeiro herbáceo, que os nutrientes presentes na água residuária não foram, por si só, suficientes para incrementar valores às variáveis altura, diâmetro caulinar e área foliar para o algodão herbáceo mas sua combinação com a adubação química foi capaz de influenciar as mesmas 
A.

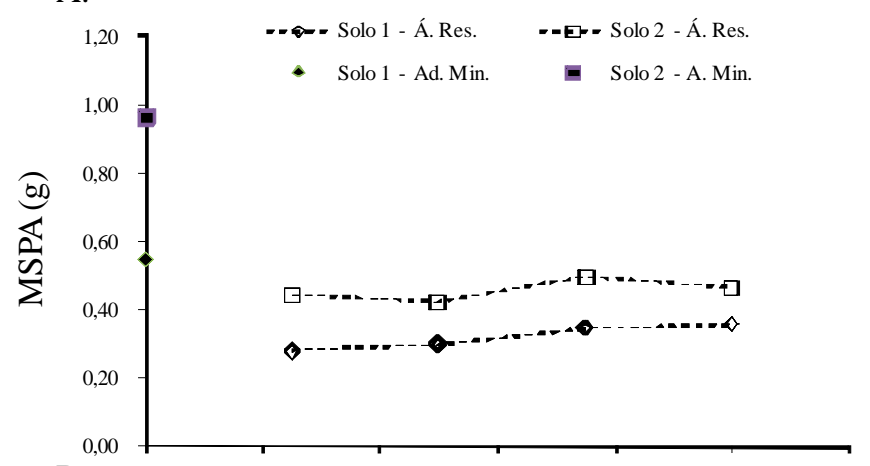

B.

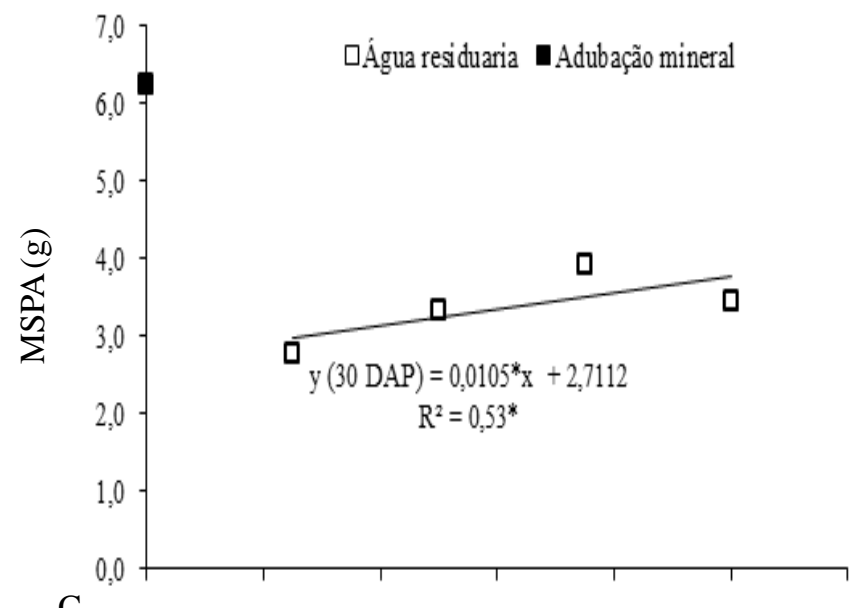

C.

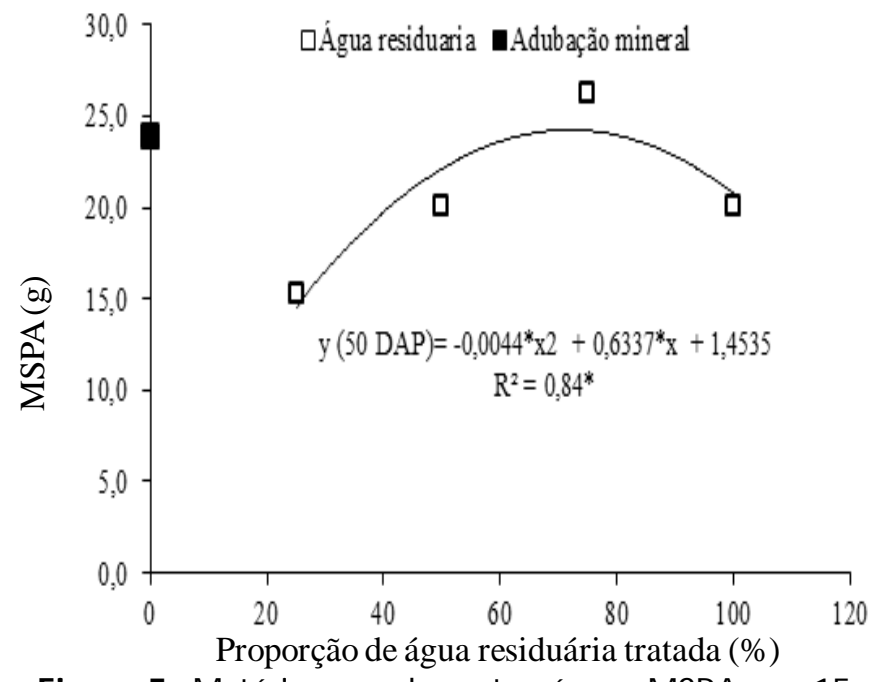

Figura 5. Matéria seca da parte aérea - MSPA aos 15 (A), 30 (B) e aos 50 DAP (C) do algodoeiro em função do aumento percentual de água residuária

variáveis, com doses menores de adubos químicos, denotando o grande potencial nutritivo e sua capacidade de economia de até $90 \mathrm{~kg} \mathrm{~N} \mathrm{ha}{ }^{-1}$ com adubos químicos.

\section{Conclusões}

1. Os valores máximos do IVE e PG encontrados em função das proporções de água residuária, foram de 68,57\% (33, 83 plântula dia-1) e $100 \%(94,45 \%)$ respectivamente.
A.
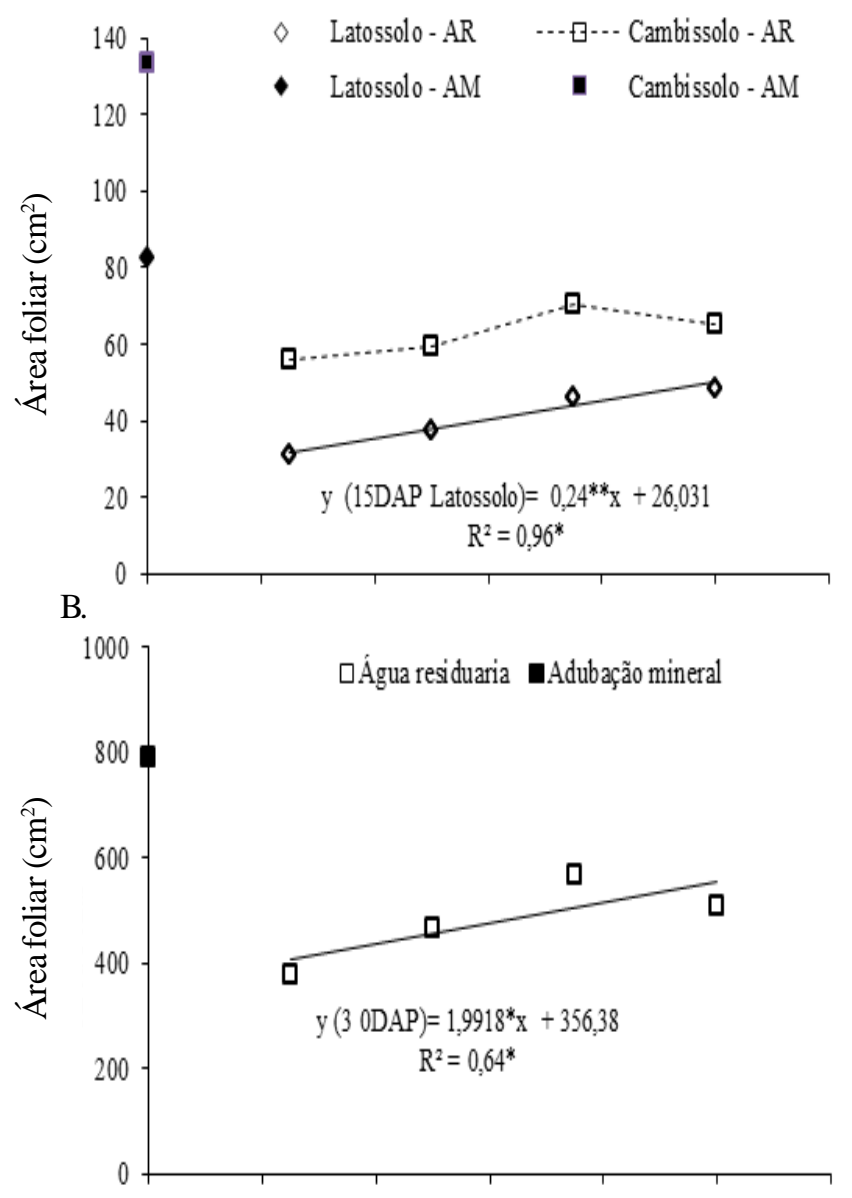

C.

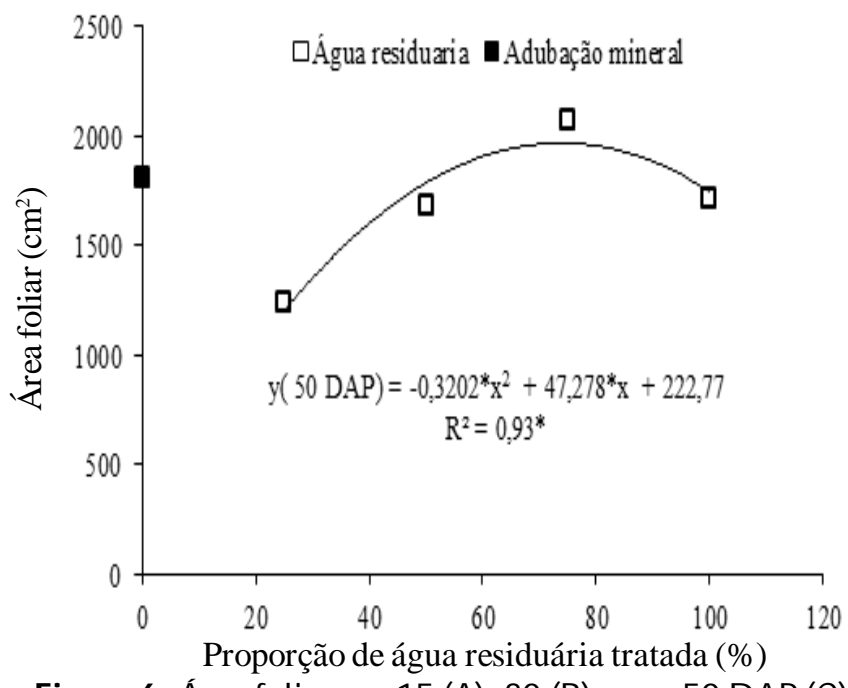

Figura 6. Área foliar aos 15 (A), 30 (B) e aos 50 D AP (C) do algodoeiro em função do aumento percentual de água residuária

2. As médias de altura de plantas se apresentaram significativas aos 15 e 30 DAP em todas as proporções de água residuária aplicadas. O valor máximo de altura de planta aos 50 DAP foi de $67,30 \mathrm{~cm}$ verificados com a proporção de $100 \%$ de água residuária.

3. O DC apresentou, quando submetido ao tratamento com água residuária, resposta significativa aos 15 e 30 DAP.

4. A área foliar foi influenciada pela irrigação com água

R. Bras. Eng. Agríc. Ambiental, v.16, n.2, p.200-208, 2012. 
residuária aos 15 e 30 DAP quando comparada com a adubação convencional do tratamento controle; o valor máximo encontrado foi de $1697,30 \mathrm{~cm}^{2}$ com a aplicação de $73,82 \%$ de água residuária.

\section{LITERATURA CITADA}

Alves, W. W. A.; Azevedo, C. A. V. de; Dantas Neto, J.; Sousa, J. T. de; Lima, V. L. A. Águas residuárias e nitrogênio: efeito na cultura do algodão marrom. Revista Verde de Agroecologia e Desenvolvimento Sustentável, v.4, p.16-23, 2009a.

Alves, W. W. A.; Dantas Neto, J.; Andrade, A. R. S.; Madeiros, L. B.; Azevedo, C. A. V. de; Santos, J. W.; Beltrão, N. E. M. Componentes da produção do algodão de fibra marrom irrigado com água residuária tratada. Revista Brasileira de Engenharia Agrícola e Ambiental, v.9, p.207-211, 2005.

Alves, W. W. A.; Dantas Neto, J.; Lima, V. L. A. de. Área foliar do algodoeiro irrigado com água residuária adubado com nitrogênio e fósforo. Revista Verde de Agroecologia e Desenvolvimento Sustentável, v.4, p.41-46, 2009 b.

Bezerra, B. G.; Fideles Filho, J. Análise de crescimento da cultura do algodoeiro irrigada com águas residuárias.Revista Ciência Agronômica, v.40, p.339-345, 2009.

Bezerra, L. J. D.; Lima, V. L. A. de; Andrade, A. R. S.; Alves, V. W.; Azevedo, C. A. V. de; Guerra, H. O. C. Analise de crescimento do algodão colorido sob os efeitos da aplicação de água residuária e biossólidos. Revista Brasileira de Engenharia Agrícola e Ambiental, v.1, p.333338, 2005.

Carmo Filho, F.; Oliveira, O. F. Mossoró: Um município do semi-árido nordestino, caracterização climática e aspecto florístico. Mossoró: ESAM, 1995. 62p. Coleção Mossoroense, série $\mathrm{B}$

EMBRAPA - Empresa Brasileira de Pesquisa Agropecuária. Sistema brasileiro de classificação de solos. Rio de Janeiro: CNPS, 1997.212p. Documento, 1

EMBRAPA - Empresa Brasileira de Pesquisa Agropecuária. Calagem e adubação do algodoeiro no Cerrado. Planaltina: CNPA, 2006. 16p. Documento, 92

Ferreira, O. E.; Beltrão, N. E. de M.; König, A. Efeitos da aplicação de água residuária e nitrogênio sobre o crescimento e produção do algodão herbáceo. Revista Brasileira de Oleaginosas e Fibrosas, v.9, p.893-902, 2005.
Ferreira, O. E.; König, A.; Beltrão, N. E. de M.; Ceballos, B. S. O. de ; Dias, J. M.; Paiva Junior, H. B. Uso de água residuária tratada no crescimento do algodoeiro herbáceo no nordeste brasileiro. In: Congresso Brasileiro de Engenharia Sanitária e Ambiental, 22, 2003, Joinville. Anais.... Joinville: PROSAB, 2003. CD-Rom.

Fideles Filho, J. Nóbrega, J. Q.; Sousa, J. T.; Dantas, J. P. Comparação dos efeitos de água residuária e de poço no crescimento e desenvolvimento do algodoeiro. Revista Brasileira de Engenharia Agrícola e Ambiental, v.9, p.328332, 2005.

Rodrigues, L. N.; Nery, A. R.; Fernandes, P. D.; Beltrão, N. E. de M.; Gheyi, H. R. Crescimento e produção de bagas da mamoneira irrigada com água residuária doméstica. Revista Brasileira de Engenharia Agrícola e Ambiental. v.13, p.825835, 2009.

Santos, K. D.; Henrique, I. N.; Sousa, J. T.; Leite, V. D. Utilização de esgoto tratado na fertirrigação agrícola. Revista Biologia e Ciências da Terra. SuplementoEspecial, n. 1/2, p.1-7, 2006.

Silva, M. B. R.; Fernandes, P. D.; Dantas Neto, J.; Nery, A. R.; Rodrigues, L. N.; Viégas, R. A. Crescimento e produção do pinhão-manso irrigado com água residuária sob condições de estresse hídrico. Revista Brasileira de Engenharia Agrícola e Ambiental, v.15, p.621-629, 2011.

Silva, V. F.; Sousa, J. T.; Vieira, F. V.; Santos, K. D. Tratamento anaeróbio de esgoto doméstico para fertirrigação. Revista Brasileira de Engenharia Agrícola e Ambiental, v.9, p.186190, 2005

Siqueira, E. C.; Gheyi, H. R.; Beltrão, N. E. de M.; Soares, F. A. L.; Barros Júnior, G.; Cavacalti, M. L. F. Crescimento do algodoeiro colorido sob diferentes níveis de salinidade da água de irrigação. Revista Brasileira de Engenharia Agrícola e Ambiental, v.9, p.263-267, 2005.

Sousa, J. T. de; Souto, S. M.; Henrique, I. N.; Oliveira, J. B. Efluentes tratados utilizados na agricultura. In: Simpósio Brasileiro de Recursos Hídricos 15, 2003, Curitiba. Anais... Curitiba: ABRH, 2003. p.1-12.

Sousa, J. T. de; van Haandel, A. C.; Cavalcanti, P. F. F.; Figueiredo, A. M. F.Tratamento de esgoto para uso na agricultura do semi-árido nordestino. Revista de Engenharia Sanitária e Ambiental, v.10, p.260-265, 2005.

van Der Hoeck, W.; Hassan, U.M.; Ensink, J. H. J.; Feenstra, S.; Raschid-Sally, L.; Munir, S.; Aslam, R.; Alim, N.; Hussain, R.; Matsuno, Y. Urban wastewater: A valuable resource for agriculture. A case study from Horoonabad, Sri Lanka: International Water Management Institute, 2002. 20p. Research Report, 63. 